\title{
Biopsy-confirmed Genitourinary Tuberculosis in a Secondary Health Care Hospital: An Evidence-based Clinical Review
}

This article was published in the following Dove Press journal: Research and Reports in Urology

Johannes Cansius Prihadi ${ }^{1,2}$ Andika Chandra Putra $\mathbb{D}^{3,4}$ Yuvi Wahyudi ${ }^{2}$

'Department of Surgery, Urology Division, School of Medicine and Health Sciences, Atma Jaya Catholic University, Jakarta, Indonesia; ${ }^{2}$ Department of Urology, St. Carolus Hospital, Jakarta, Indonesia; ${ }^{3}$ Department of Pulmonology and Respiratory Medicine, Faculty of Medicine, Universitas Indonesia, Jakarta, Indonesia; ${ }^{4}$ Department of Pulmonology and Respiratory Medicine, St. Carolus Hospital, Jakarta, Indonesia
Correspondence: Johannes Cansius Prihadi Department of Surgery, Urology Division, School of Medicine and Health Sciences, Atma Jaya Catholic University, Jl. Pluit Selatan Raya No. 19, RT.2I/RW.8, Penjaringan, Kec. Penjaringan, Kota Jkt Utara, Daerah Khusus Ibukota, Jakarta, 14440, Indonesia Tel +62216694366

Email johannes.cansius@atmajaya.ac.id
Introduction: Tuberculosis (TB) is a worldwide disease and remains a major public health problem in developing countries, with $95 \%$ of cases occurring in developing countries, including Indonesia. It is caused by Mycobacterium tuberculosis, an acid-fast aerobic bacillus. When M. tuberculosis infects other than lung, it is called extrapulmonary tuberculosis (EPTB). Among other organs, genitourinary tuberculosis (GUTB) is responsible for $30-40 \%$ of all EPTB cases.

Methods: The study was conducted in a secondary health-care hospital in central Jakarta over a five-year period. We took data from hospital's medical records and collected all the positive histopathological reports on biopsied tissue of the genitourinary tract from 2014-2019.

Results: Eleven patients showed positive histopathological results for TB on their biopsied genitourinary tissue. The genitourinary tracts involved were as follows: prostate $(n=2)$, kidney $(n=1)$, ureter $(n=2)$, epididymis $(n=1)$, epididymo-orchitis $(n=1)$, bladder $(n=4)$. All of them presented with specific genitourinary symptoms, such as lower urinary tract symptoms (LUTS) $(n=8)$, dysuria $(n=9)$, urinary retention $(n=2)$, flank pain $(n=6)$, and incontinence $(n=1)$. Nine of 11 patients $(81.8 \%)$ exhibited systemic manifestations, with fever being the most common $(n=8)$, followed by malaise $(n=6)$, dyspepsia syndrome $(n=4)$, and weight loss $(n=3)$.

Discussion: Consistent with other studies, our research found that the prevalence of GUTB is substantially decreased with advancing age. Kidney is the most common site infected in GUTB infection. GUTB is easily overlooked, because its signs and symptoms are usually typical of a conventional bacterial cystitis.

Conclusion: Because of its insidious nature and late-onset symptoms, diagnosis of GUTB is often late to approach, leading to higher morbidity and even mortality rate. This leads into further complications of the disease, which are largely preventable by a correct and timely diagnosis followed by appropriate therapy.

Keywords: tuberculosis, genitourinary, extrapulmonary

\section{Introduction}

Tuberculosis (TB) is a worldwide disease and remains a major public health problem in developing countries. Approximately $95 \%$ of cases occur in developing countries, including Indonesia. ${ }^{1-3}$ To date, annual TB incidence in Indonesia has reached 1,020,000 cases each year, with an incidence rate of 391 per 100,000 of the population, and currently is the fourth leading cause of death in Indonesia. ${ }^{4}$

Tuberculosis is a multisystem disease with myriad presentations and manifestations, and can affect any organ or tissue, excluding hair and nails. ${ }^{5}$ It is caused by 
Mycobacterium tuberculosis, an acid-fast aerobic bacillus. M. tuberculosis is the most virulent Mycobacterium pathogen known to the human species. Its slow replication rate accounts for the insidious nature of the infection and the resistance to ordinary antibiotics. ${ }^{1} M$. tuberculosis infections usually begin by inhalation of aerosol droplets containing tubercle bacilli directly expectorated from an individual with pulmonary disease. Lung is the most common organ infect by mycobacterium tuberculosis but when M. tuberculosis infects other than lung, it is called extrapulmonary tuberculosis (EPTB). Some types of EPTB, such as meningitis TB and miliary $\mathrm{TB}$, can substantially increase the rate of mortality in various populations. Among other organs, genitourinary tuberculosis (GUTB) is responsible for $30-40 \%$ of all EPTB cases, second only to lymphonodal TB. GUTB is also present in $2-20 \%$ of patients with pulmonary $\mathrm{TB}$, with a rise of $15-20 \%$ more cases in developing countries. ${ }^{5,6}$ GUTB mainly spreads through a hematogenous route from previous pulmonary infection. ${ }^{7}$

In the past few decades, studies have shown that EPTB cases, including GUTB, comprise an increased proportion of total TB cases. Of the 6.3 million new TB cases recognized by WHO in 2017, 16\% were EPTB. Despite these facts and data, research is scarce and limited. ${ }^{8}$ With this report, we aim to analyze the prevalence and clinical manifestations of GUTB in our B-type hospital (secondary health care), as an effort to raise physicians' awareness of GUTB disease in our daily practice.

\section{Methods}

The study was conducted at a secondary health-care hospital in central Jakarta over a five-year period. We took data from hospital's medical records and collected all the histopathological reports on biopsied tissue of the genitourinary tract from 2014-2019, looking for patients who had a positive result of TB. We then took those data to be investigated further.

\section{Results}

Eleven patients with positive histopathological results for TB, showing extensive caseous tissue with occasional granulomas composed of epitheloid cells and Langhans giant cells with surrounding lymphocytes (as shown in Figure 1) on their biopsied genitourinary tissue, were taken and retrospectively analyzed. There were a total of 750 genitourinary biopsy data appearing from May 2014 to January 2019. All the diagnoses of GUTB were made

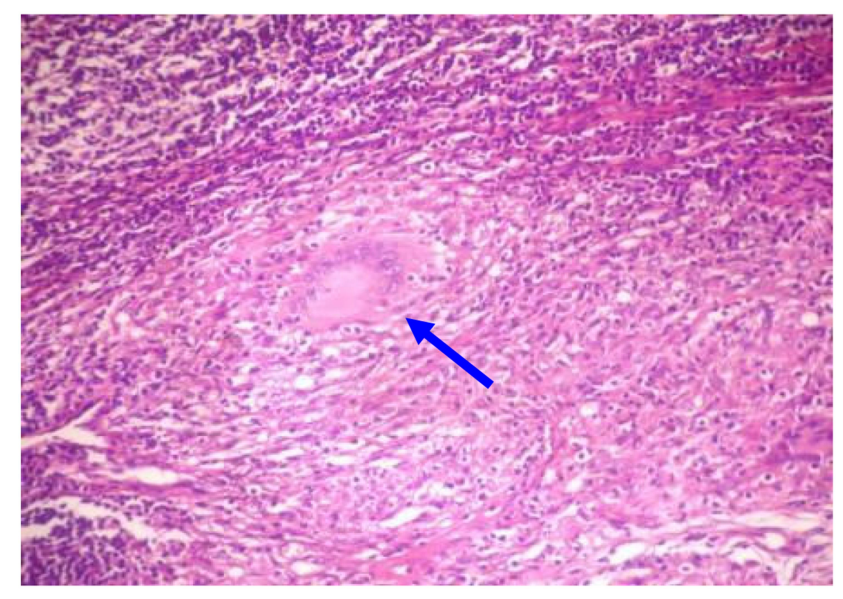

Figure I Histopathology of genitourinary tuberculosis showing extensive caseous tissue with occasional granulomas composed of epithelioid cells and Langhans giant cells with surrounding lymphocytes (indicated by blue arrow).

from histopathology examination under the microscope by the hospital's pathology anatomy specialists. The median age was 43 years, ranging from $22-70$ years, with six of them were male, and six were female (Table 1).

The genitourinary tracts involved were as follows: prostate $(\mathrm{n}=2)$, kidney $(\mathrm{n}=1)$, ureter $(\mathrm{n}=2)$, epididymis $(n=1)$, epididymo-orchitis $(n=1)$, bladder $(n=4)$. Among 11 patients, four of them had pulmonary TB (36.4\%). All of our patients were diagnosed after they were admitted. The median duration of symptoms between first onset of symptoms and diagnosis was five months (ranging between one and 12 months). All of them presented with a specific genitourinary symptom, such as lower urinary tract symptoms (LUTS) $(\mathrm{n}=8)$, dysuria $(\mathrm{n}=9)$, urinary retention $(n=2)$, flank pain $(n=6)$, and incontinence $(n=1)$. Nine of 11 patients $(81.8 \%)$ exhibited systemic

Table I Demographic Status of GUTB Patients in St Carolus Hospital (2014-2019)

\begin{tabular}{|l|c|}
\hline Age & Patients n (\%) \\
\hline Total patients & $\mathrm{II}$ \\
\hline Gender & \\
Male & $6(54.5)$ \\
Female & $5(45.5)$ \\
\hline Age distribution (years) & \\
$20-29$ & $2(18.2)$ \\
$30-39$ & $4(36.4)$ \\
$40-49$ & $2(18.2)$ \\
$50-59$ & $2(18.2)$ \\
$60-69$ & $1(9.1)$ \\
$70-79$ & $1(9.1)$ \\
\hline
\end{tabular}


manifestations, with fever being the most common $(n=8)$, followed by malaise $(n=6)$, dyspepsia syndrome $(n=4)$, and weight loss $(n=3)$ as seen in Table 2.

Of the biochemistry data shown by patient's lab results, leukocytosis presented the most $(n=7)$, followed by anemia $(n=4)$, kidney failure $(n=3)$, electrolyte imbalance $(n=2)$, and low albumin serum $(n=1)$. From urinalysis result, leukocyturia was the most common lab finding appearing amongst our patients $(\mathrm{n}=10)$, hematuria $(n=8)$, proteinuria $(n=5)$, positive for leukocyte esterase in urine $(n=3)$, and pyuria $(n=2)$ followed respectively, as shown in Table 3.

From imaging diagnosis, six of them (54.5\%) had an abdominal ultrasound, and two patients received a whole-abdominal $\mathrm{CT}$ scan before their admission to the hospital. Four patients $(36.4 \%)$ had hydronephrosis and hydroureter, two (18.2\%) had a thickening of bladder wall suggesting cystitis, one (9.1\%) had an abscess inside his scrotum and a left-sided orchitis, and one $(9.1 \%)$ had a right-sided hydrocele, as seen in Table 4.

Of these patients, all of them received medical treatment $(100 \%)$. No patients went untreated. Two of them $(18.2 \%)$ had only genitourinary-related surgery (no medical therapy), three patients (27.3\%) had medication only,

Table 2 Clinical Characteristics of GUTB Patients in St Carolus Hospital (2014-2019)

\begin{tabular}{|l|c|}
\hline Characteristics & Patients n (\%) \\
\hline GUTB location & $2(18.9)$ \\
Prostate & $1(9.1)$ \\
Kidney & $2(18.9)$ \\
Ureter & $4(36.4)$ \\
Bladder & $1(9.1)$ \\
Epididymis & $1(9.1)$ \\
Epididymo-orchitis & \\
\hline Systemic symptoms & $8(72.7)$ \\
Fever & $6(54.5)$ \\
Malaise & $3(27.3)$ \\
Weight loss & $4(36.4)$ \\
Dyspepsia & \\
\hline Genitourinary tract symptoms & $8(72.7)$ \\
LUTS & $9(81.8)$ \\
Dysuria & $2(18.9)$ \\
Urinary retention & $6(54.5)$ \\
Flank pain & $1(9.1)$ \\
Incontinence & \\
\hline
\end{tabular}

Table 3 Biochemistry Results of GUTB Patients in St Carolus Hospital (2014-2019)

\begin{tabular}{|l|c|}
\hline Laboratory & Patients n (\%) \\
\hline Blood work & \\
Anemia & $4(36.4)$ \\
Leucocytosis & $7(63.6)$ \\
Electrolyte imbalance & $2(18.2)$ \\
Low albumin & $1(9.1)$ \\
Kidney failure & $3(27.3)$ \\
\hline Urinalysis & \\
Hematuria & $8(72.7)$ \\
Leukocyturia & $10(90.9)$ \\
Proteinuria & $5(45.5)$ \\
Pyuria & $2(18.2)$ \\
High leukocyte esterase & $3(27.3)$ \\
\hline
\end{tabular}

Table 4 Imaging Studies of GUTB Patients in St Carolus Hospital (2014-2019)

\begin{tabular}{|l|c|}
\hline Imaging & Patients n (\%) \\
\hline Abdominal ultrasound & \\
Hydronephrosis & $2(18.2)$ \\
Hydroureter & $2(18.2)$ \\
Cystitis & $2(18.2)$ \\
Abscess scrotum & I (9.1) \\
Orchitis & I (9.1) \\
Hydrocele & I (9.1) \\
\hline Whole abdominal CT scan & \\
Hydronephrosis & $2(18.2)$ \\
Hydroureter & $2(18.2)$ \\
Nephrolithiasis & I (9.1) \\
\hline
\end{tabular}

and six patients (54.5\%) had both medication and surgical treatment in our hospital.

\section{Discussion}

TB is ancient disease, but to this date infection of M. tuberculosis is still the common cause of morbidity and mortality especially in developing countries such as Indonesia. Globally, the prevalence rate of new TB cases can go up to 8-10 million cases each year, with a mortality rate of over 1.9-3 million deaths annually. ${ }^{7}$ In developing countries, there is an annual incidence of 100-450 new cases per 100.000 inhabitants, with up to 2-3 million death each year. ${ }^{1,9,10}$ In Indonesia, annual TB incidence has reached up to 1.020 .000 cases each year, with an incidence rate at 391 per 100,000 of the population, and currently is the fourth leading cause of death in Indonesia. ${ }^{4}$ Despite 
these facts and data, research on $M$. tuberculosis infection in genitourinary tract is still scarce and limited, that is why we aimed to analyze the prevalence and clinical manifestations of GUTB in our hospital as an effort to raise physicians' awareness of GUTB disease in our daily practice.

Consistent with other studies, our research found that the prevalence of GUTB is substantially decreased with advancing age. ${ }^{8}$ Figueiredo and Lucon, and Tocaceli et al stated that GUTB has a predominance of 30-50 years. $^{1,2,6,10}$ While Merchant et al has a mean age of 40.7 years ranging from 5-90 years. ${ }^{3}$ Similar to this, the average age of our patients was 44.7 years, with median interval of 43 years (Figure 2). This means, as stated in other studies previously mentioned, that in developing countries such as Indonesia, GUTB patients are predominantly young adults. ${ }^{1-3,7,8}$

Huang et al, and few other studies stated that the kidney is the most common site infected in GUTB infection. ${ }^{1,3,11,12}$ Eastwood et al in their research found that epididymis and prostate were the most common site being infected in men. ${ }^{9}$ In our research, we find that the bladder was the site that was most infected (36.4\%), followed by ureter and prostate $(18.9 \%)$, respectively. We have only one patient that presented with renal TB (9.1\%). This shows that GUTB can easily infect any organ in GUTB with no specific presentation whatsoever, making this disease truly a diagnostic challenge for physicians everywhere.

In terms of signs and symptoms, GUTB is easily overlooked. Signs and symptoms are usually typical of a conventional bacterial cystitis. Suspicions usually arise if UTI is not treatable with many types of regular antibiotics. ${ }^{9}$ In the cases we reported here, the median duration of symptoms between first onset of symptoms

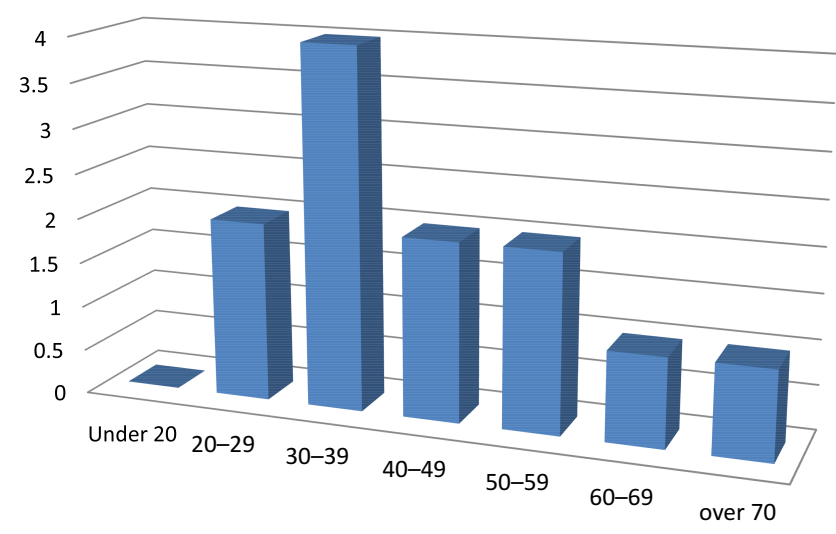

Figure 2 Age distribution of GUTB patients 2014-2019. and diagnosis was five months (ranging between one and 12 months). This is consistent with other findings by Huang et al, who stated that the median duration of symptoms was around four months. ${ }^{12}$ Fever was the most common constitutional symptom that appeared $(72.7 \%)$, followed by malaise $(54.5 \%)$, weight loss $(27.3 \%)$, and dyspepsia (36.4\%). Urinary symptoms also appeared with the most complaints made of dysuria (81.8\%), followed by LUTS (72.7\%), flank pain (54.5\%), urinary retention $(18.9 \%)$, and urinary incontinence $(9.1 \%)$. These findings also have a similar result compared to those found in studies by Huang et al and Figueiredo et al ${ }^{6,12}$ All GUTB diagnoses were made after patients were hospitalized and biopsied by our pathologist. Patients also had multiple histories of repeated visits to the doctor. This meant that GUTB was so rarely thought of by physicians, which often made the diagnosis late. This disease should be expected in patients with unexplained recurrent or chronic UTI, especially if it occurs in endemic areas such as Indonesia. $^{2}$

Our research is subject to some limitations. Our retrospective research only collected data of GUTB cases from our hospital, rather than national surveillance data, which resulted in a very small scope of findings that could be investigated further. We do hope there would be larger studies in the future. A systematic search for GUTB, regardless of symptoms, is warranted for early case detection. Any attempts to estimate the prevalence of GUTB are also useful.

\section{Conclusion}

Because of its insidious nature and late-onset symptoms, diagnosis of GUTB is often established late, leading to higher morbidity and even mortality rates. A worrying underestimation of GUTB is actually evident. This may be responsible for the delayed diagnosis leading into further complications of the disease itself, which are largely preventable by a correct and timely diagnosis followed by an appropriate therapy. Urgent strategies are warranted to help raise clinician's awareness, especially urologists, about establishing earlier detection of GUTB in developing countries such as Indonesia.

\section{Consent}

Permission to use information from our Anatomical Pathology database or repository for this study was given from the department without the need for institutional 
approval to publish this study. Patient consent to review their medical records was not required by the IRB since all data that we acquired has been kept anonymised, for the benefit of developing educational sciences, and it covers patient data confidentiality and compliance with the Declaration of Helsinki.

\section{Acknowledgment}

We would like to express our gratitude to Dr Renaningtyas Tambun, SpPA in the Department of Pathological Anatomy of St Carolus Hospital, for help in examining all the tissue samples we sent, which has helped us a lot in this study.

\section{Disclosure}

The authors report no conflicts of interest in this work.

\section{References}

1. Figueiredo A, Lucon A. Urogenital tuberculosis: update and review of 8961 cases from the literature. Rev Urol. 2008;10(3):207-215.

2. Toccaceli S, Stella LP, Diana M, et al. Renal Tuberculosis: a case report. G Chir. 2015;36:76-78.
3. Merchant S, Bharati A, Merchant N. Tuberculosis of the genitourinary system-urinary tract tuberculosis: renal tuberculosis: part 1 . Indian J Radiol Imaging. 2013;23(1):46-63. doi:10.4103/09713026.113615

4. World Health Organization. TB: global tuberculosis report. Geneva: WHO; 2018

5. Kulchavenya E. Extrapulmonary Tuberculosis: are statistical report accurate? Ther Adv Infect Dis Vol. 2014;2(2):61-70.

6. Figuereido A, Lucon A, Gomes CM, Srougi M. Urogenital tuberculosis: patient classification in seven different groups according to clinical and radiological presentation. Int Braz J Urol Vol. 2008;34 (4):422-432. doi:10.1590/S1677-55382008000400004

7. Caliskan S, editor. Diagnosis of genitourinary tuberculosis. In: Tuberculosis. Dover, DE: SMGroup; 2016.;1-8

8. Pang Y, An J, Shu W, et al. Epidemiology of extrapulmonary tuberculosis among inpatients in China 2008 - 2017. Emerg Infect Dis. 2019;25(3):457-464. doi:10.3201/eid2503.180572

9. Eastwood JB, Corbishley CM, Grange JM. Tuberculosis and the kidney. JASN. 2001;12(6):1307-1314.

10. Figuereido AA, Lucon AM, Junior RF, Srougi M. Epidemiology of urogenital tuberculosis worldwide. Int J Urol. 2008;15:827-832. doi:10.1111/j.1442-2042.2008.02099.x

11. Amaya-Tapia G, Aguirre-Avalos G. Urinary-tract tuberculosis. IntechOpen. 2018.

12. Huang TY, Hung CH, Hsu WH, et al. Genitourinary tuberculosis in Taiwan: a 15-year experience at a teaching hospital. J Microbiol Immunol Infection. 2019;52:312-319. doi:10.1016/j.jmii.2018.10.007

\section{Publish your work in this journal}

Research and Reports in Urology is an international, peer-reviewed, open access journal publishing original research, reports, editorials, reviews and commentaries on all aspects of adult and pediatric urology in the clinic and laboratory including the following topics: Pathology, pathophysiology of urological disease; Investigation and treatment of urological disease; Pharmacology of drugs used for the treatment of urological disease. The manuscript management system is completely online and includes a very quick and fair peer-review system, which is all easy to use. Visit http://www.dovepress.com/ testimonials.php to read real quotes from published authors. 